\title{
Successful IVF Pregnancy in a Young Patient with Stromal Leydig Cell Tumour and Adenofibroma Simultaneously
}

\author{
Smriti Khandelwal ${ }^{1}$, Deepti Shrivastava ${ }^{2}$ \\ ${ }^{1}$ Department of Obstetrics and Gynaecology, Datta Meghe Institute of Medical Sciences, \\ Sawangi, Wardha, Maharashtra, India. ${ }^{2}$ Department of Obstetrics and Gynaecology, Datta \\ Meghe Institute of Medical Sciences, Sawangi, Wardha, Maharashtra, India.
}

\section{INTRODUCTION}

Sertoli Leydig cell tumour of ovary belonging to the category of sex cord stromal tumours is an extremely rare neoplasm accounting for $<0.5 \%$ of all primary ovarian neoplasms. The tumour has varied clinical and histopathological presentations often overlapping with other common entities making the diagnosis difficult.

Adenofibroma belong to the category of surface epithelial tumours of ovary. Serous adenofibroma are lesser known variants of this class of surface epithelial tumours. They are relatively benign and usually bilateral that contains both epithelial and fibrous stromal components. We present a case of 27 years old nulliparous woman with complains of pain in abdomen in right iliac fossa and irregular periods with histopathological examination revealing stromal Leydig cell tumour with adenofibroma..

Sertoli Leydig cell tumour is a rare ovarian tumour composed of sex cord (Sertoli cells) and stromal (Leydig cells) elements. It may occur sporadically or in patients harboring DICER 1 mutations. It expresses general sex cord markers like inhibin, calretinin, SF1, FOXL2 and CD56.

Terminology used for Sertoli Leydig cell tumour are well differentiated, moderately/intermediate and poorly differentiated grades, Sertoli Leydig cell tumour with heterologous elements, Sertoli Leydig cell retiform variant. Clinically androgenic symptoms (virilization) are most common manifesting as hirsutism, clitoromegaly, breast atrophy and menstrual irregularity or amenorrhea. It may also present with pelvic pain and pelvic mass. Estrogenic hormonal symptoms are rare. Ovarian cystadenofibroma is a rare benign tumour of ovary commonly occurring in women aged 15-65 years. On routine imaging methods it may mimic a malignant neoplasm but the fibrous component often gives a characteristic MRI appearance helping to differentiate it from malignant ovarian tumours.

\section{PRESENTATION OF CASE}

A 27-year-old nulliparous woman was brought to gynecology OPD with complains of pain in right iliac fossa since 15 days and irregular menses since 6 years. She had an ultrasonography report of outside with an ovarian cystic mass measuring $35 \mathrm{~cm}$ x 24 $\mathrm{cm} \times 11 \mathrm{~cm}$ with serous cyst adenoma. Her CA 125 was $123 \mathrm{IU} / \mathrm{ml}$. An exploratory laparotomy was planned, and SOS hysterectomy was explained to the patient. She underwent exploratory laparotomy and an ovarian mass was seen arising from left ovary, stalk of which was adherent to sigmoid mesocolon. Multiple para fimbrial and para ovarian cyst were also present. The cyst was removed and sent for frozen section which revealed borderline serous cyst adenoma. Clinically the intraoperative picture seemed of serous adenofibroma and on histopathological examination features were suggestive of stromal Leydig cell tumour and adenofibroma. Since the patient was eager to conceive hence option of oocyte donation and IVF was advised after complete ovarian suppression by GnRH analogue. The patient opted for IVF and on follow up she came with a UPT positive test and an ultrasonography with 5 weeks pregnancy.
Corresponding Author: Dr. Deepti Shrivastava, Professor,

Department of Obstetrics and Gynaecology, Datta Meghe Institute of Medical Sciences, Sawangi, Wardha, Maharashtra, India. E-mail: deepti_shrivastava69@gmail.com

DOI: $10.14260 / j e m d s / 2020 / 352$

Financial or Other Competing Interests: None.

How to Cite This Article:

Khandelwal S, Shrivastava D. Successful IVF pregnancy in a young patient with stromal leydig cell tumour and adenofibroma simultaneously. J. Evolution Med. Dent. Sci. 2020;9(20):1613-1615, DOI: 10.14260/jemds/2020/352

Submission 13-02-2020,

Peer Review 27-04-2020,

Acceptance 04-05-2020,

Published 18-05-2020.

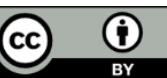



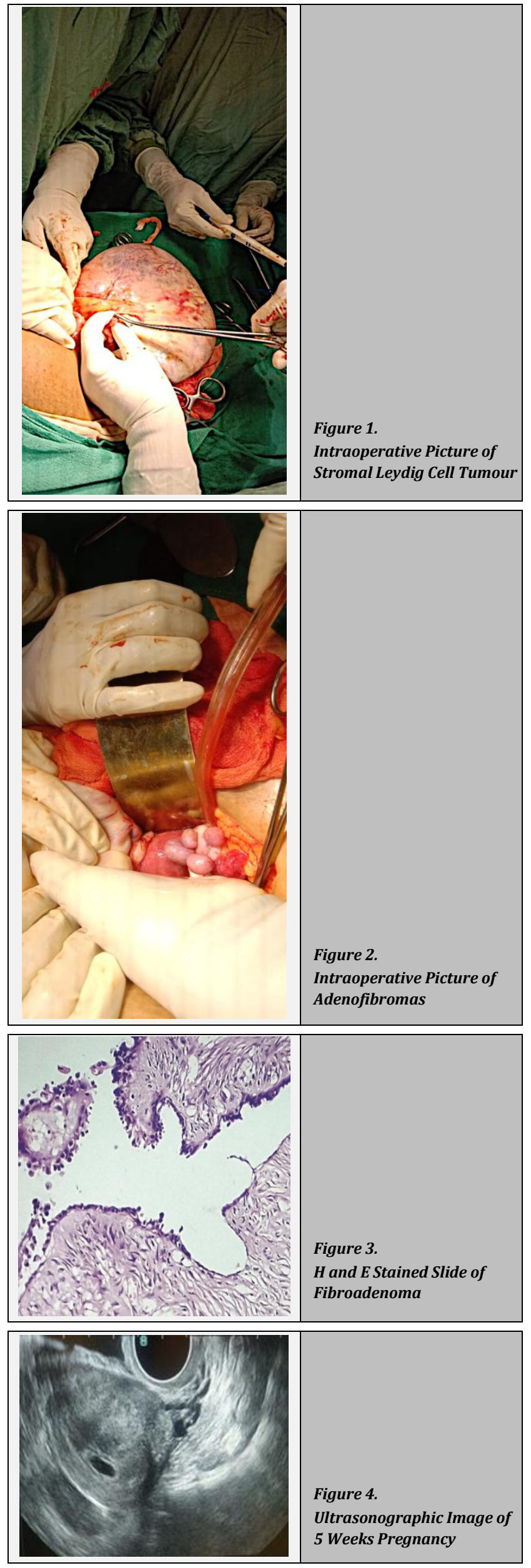

\section{DISCUSSION}

Sertoli Leydig cell tumours are rare ovarian neoplasm more frequently seen in young women with mean age of 25 years.(1) They belong to sex cord stromal tumors and are composed of granulosa cells, theca cells, Sertoli cells, Leydig cells and fibroblasts of stromal origin and may occur singly or in various combination.(2) It usually presents in reproductive age group with symptoms of excess hormone production (hyperandrogenism) or a mass occupying lesion. Hyperandrogenism produced by these tumours have symptoms onset faster than other causes of hyperandrogenism.

The initial best imaging technique for diagnosis is sonography where this tumour exhibit solid,(3) or mixed component and are mostly unilateral. Colour doppler can be used for differentiating neoplastic component where highly vascular masses may suggest of malignant component. Further imaging techniques like MRI, CT and positron imaging tomography can be used for further categorization of Sertoli Leydig cell tumour.(4)

Macroscopically it may range from 2 to $35 \mathrm{cms}$. These tumours are not characteristic when it comes to their gross appearance, well circumscribed tumours appearing encapsulated with smooth or bosselated outer surface. Sertoli like cell and Leydig cells lining tubular structures in variation are well differentiated.

Epithelial component with Sertoli type cells in form of solid cords, true tubules, trabeculae, solid tubules which are set in mesenchymal stroma in abundance containing collagen, spindle cells in varying proportion with Leydig cells arranged in clusters, sheets or singly are seen in less well differentiated tumours. Small group of Leydig cells and tubules which are imperfectly formed or structures which seems to be irregular cord like packed in sheets of spindle cells are seen in poorly differentiated tumours.

Ovarian cystadenofibroma is a surface epithelial tumour classified as serous, mucinous, endometrioid, clear cell and mixed and exhibit fibrous stroma in variable amounts in all subtypes.(5) Mostly benign but borderline and malignant components are also present and are classified on basis of degree of epithelial proliferation and relation to stromal component.

A benign solid tumour which mimics a fibroma and histologically contains both fibromatous tissue as well as glandular component. The solid component of these tumours mimic malignant component but a frozen section intraoperative proves helpful in differentiating it from malignancy. Because of its heterogenous appearance a USG often misses the definite diagnosis and MRI proves to be the modality of choice in these complex tumours.(6)

\section{CONCLUSIONS}

Though the presentation and the laboratory findings of the woman were suggestive in making a diagnosis of malignant ovarian tumour but complete evaluation of woman should be done keeping in mind the nulliparous state of the woman and 
her wish to conceive. A conservative surgery and with IVF, reproductive life of the woman can be maintained, and further pregnancy can be made possible.

\section{REFERENCES}

[1] Gautam P, Rao M, Gothwal M, et al. Sertoli-Leydig cell tumor of ovary: a rare case report with heterologous elements and focal marked anaplasia. Int J Appl Basic Med Res 2019;9(1):62-4.

[2] Aminimoghaddm S, Atefeh-Sadat Ebrahimi, Hashemi F. A rare ovarian tumor, leydig stromal cell tumor, presenting with virilization: a case report. Med J Islam Repub 2012;26(4):185-8.
[3] Rathi M, Budania SK, Khalid M, et al. Bilateral retiform variant of sertoli leydig cell tumour of ovary: an uncommon tumor with review of literature. J Midlife Health 2015;6(1):35-8.

[4] Gupta MM, Bahri NU, Ketan R. Sertoli-leydig cell tumor of the ovary in a young female: a case report and literature review. Saudi J Med Med Sci 2015;3(3):233-7.

[5] Lee DH. A case of mucinous cystadenofibroma of the ovary. Case Reports in Obstetrics and Gynecology 2014;2014:130530.

[6] Wasnik A, Elsayes K. Ovarian cystadenofibroma: a masquerader of malignancy. Indian J Radiol Imaging 2010;20(4):297-9. 